\title{
A concise synthesis of substituted benzoates
}

Ashley D. Carbaugh, Wesley Vosburg, Tamara J. Scherer, Christopher E. Castillo, Matthew A. Christianson, Jennifer Kostarellas, Sager J. Gosai, and Michael S. Leonard*

Department of Chemistry, Washington \& Jefferson College, 60 South Lincoln Street, Washington, PA 15301

E-mail: mleonard@washjeff.edu

\section{Dedicated to Professor Madeleine M. Joullié on the occasion of her $\mathbf{8 0}^{\text {th }}$ birthday}

\begin{abstract}
Cycloaromatization, via tandem cycloaddition - extrusion of carbon dioxide, between methyl isodehydroacetate or methyl coumalate and a variety of alkyne dienophiles has been investigated. This method provides an efficient synthesis of methyl 4-hydroxymethyl-2,6dimethylbenzoate (1), a key intermediate in the preparation of retinal-based molecular probes.
\end{abstract}

Keywords: Citric acid, cycloaromatization, methyl coumalate, methyl isodehydroacetate, retinal

\section{Introduction}

The Diels-Alder chemistry of bromo-2-pyrones has been studied in detail. ${ }^{1}$ The cycloaddition of the related coumalate esters is a process that has been underutilized in organic synthesis and methodology. ${ }^{2}$ The reactions of coumalates with olefins typically follow an inverse-electrondemand motif. ${ }^{2}$ Substituted coumalates have been used in total synthesis in two principal ways: cycloaddition with an electron-rich olefin to install a bicyclic lactone ${ }^{3}$ and for cycloaromatization. ${ }^{4}$

The synthesis of a retinal-based biological probe (2) from mesityl aldehyde has been described (Figure 1). ${ }^{5}$ A key intermediate in that synthesis was methyl 4-hydroxymethyl-2,6dimethylbenzoate (1), the preparation of which required three steps (one using carbon tetrachloride as the solvent) and provided $12 \%$ overall yield. We are interested in the preparation of similar photoaffinity analogues and consequently sought a more efficient preparation of 1. The cycloaromatization of a substituted coumalate could be such an alternative. 
<smiles>C=C=C[CH-]C=C</smiles>

Figure 1. Preparation of a retinal-based biological probe. ${ }^{5}$

The reaction of $\alpha$-pyrones with alkynes yields aryl derivatives upon extrusion of carbon dioxide (Figure 2). ${ }^{6}$ The most typical alkyne reactive partners are phenylacetylene, a propiolate, or dimethyl acetylenedicarboxylate, which suggests that the electronic requirements of the cycloaddition can follow the usual motif. However, it is also important to note that the electronrich alkyne $N, N$-diethyl-1-propyn-1-amine has a greater reactivity with some pyrone derivatives than any of the aforementioned dienophiles. ${ }^{7}$

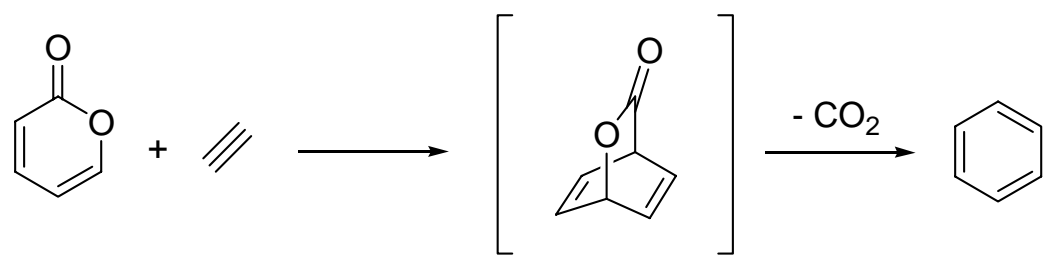

Figure 2. Tandem cycloaddition - extrusion of carbon dioxide.

The preparation of $\mathbf{1}$ via such a cycloaromatization route would require the use of propargyl alcohol or its derivatives, thereby altering the electron demand from that observed in most cases. The work described herein is aimed at developing a more efficient synthesis of 1 via this cycloaromatization route.

\section{Results and Discussion}

Cycloaddition between methyl coumalate and propargyl alcohol is a reasonably facile process, which provides methyl 4-(hydroxymethyl)benzoate in good yield after 2 hours of heating in a sealed tube (Scheme 1). The oxabicyclo species is the presumed intermediate. It has not been directly observed in the course of this particular transformation, likely due to the facile loss of carbon dioxide; however, similar bicyclic lactones have been observed in related cycloadditions where the loss of $\mathrm{CO}_{2}$ is not as favorable. ${ }^{8}$ 


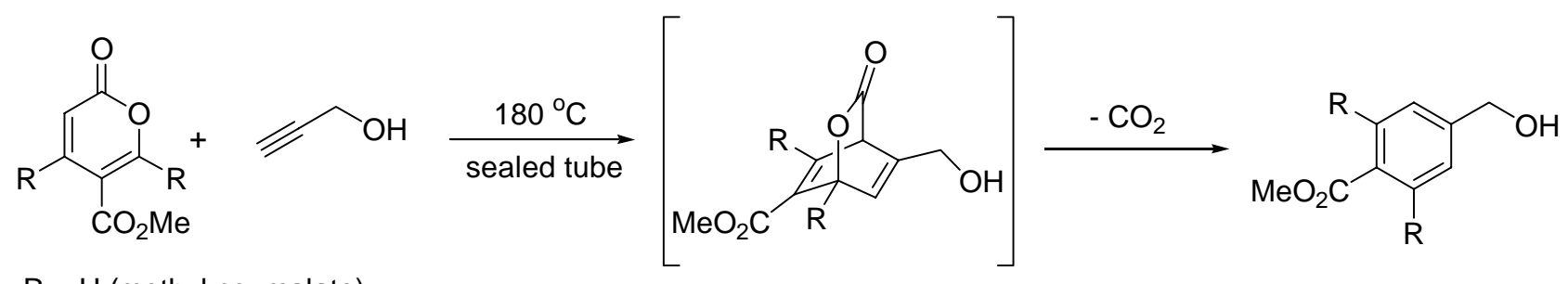

$\mathrm{R}=\mathrm{H}$ (methyl coumalate)

$\mathrm{R}=\mathrm{CH}_{3}$ (methyl isodehydroacetate)

\section{Scheme 1}

The use of methyl isodehydroacetate as a starting material to generate the target compound (1) proves to be challenging. Methyl isodehydroacetate and propargyl alcohol also undergo cycloaddition with tandem extrusion of carbon dioxide to yield the expected trisubstituted benzoate (Scheme 1); however, much longer reaction times are necessary.

Envisioning the cycloaddition as an inverse-electron-demand Diels-Alder reaction ${ }^{2}$ led to the investigation of Lewis acid catalysts, which could potentially facilitate the reaction by lowering the energy of the diene LUMO through hydrogen bonding interactions with the pyrone. However, propargyl alcohol, rather than methyl isodehydroacetate, appeared to be the optimal Lewis basic partner in this reaction, and in fact, treatment of the mixture with the broad array of Lewis acids enumerated below led only to decomposition or drastically reduced yields suggesting that hydrogen bonding with the dienophile was widening the HOMO-LUMO energy gap.

Propargyl acetate and TBS-protected propargyl alcohol also serve as viable dienophiles, providing the orthogonally protected trisubstituted benzoates 5 and 7. It was expected that protection of the hydroxyl group during the cycloaddition would enable the use of Lewis acid catalysis to facilitate the reaction. A variety of Lewis acids were screened for catalytic activity. $\mathrm{Sc}(\mathrm{OTf})_{3}{ }^{9}$ and $\mathrm{SnCl}_{4}$ led to decomposition, while acetic acid, ${ }^{10}$ trifluoroacetic acid, ${ }^{10}$ camphor sulfonic acid, ${ }^{10}$ triphenylcarbenium tetrafluoroborate, methylrhenium trioxide, ${ }^{11}$ oxazaborolidinium salts, ${ }^{12}$ and $\mathrm{Pd}(\mathrm{II})-\mathrm{BINAP}^{13}$ all led to reduced yields. Racemic tartaric acid ${ }^{10}$ did, however, provide some modest yield enhancements that were encouraging. On the basis of these results, a few $\alpha$-hydroxyacids (citric ${ }^{10}$ and lactic acid) and dicarboxylic acids (succinic and 2,3-dimethylsuccinic acid) were further examined for catalytic potential.

Of these, citric acid was the most promising. The addition of a half equivalent of citric acid led to nearly double the amount of methyl 4-acetoxymethyl-2,6-dimethylbenzoate after 4 hours of heating (Table 1). However, the rate enhancement does diminish with extended reaction time, since 10 hours of heating with the same amount of catalyst led to only $78 \%$ product, as compared with the $58 \%$ observed in the absence of citric acid. 
Table 1. Effect of citric acid on the cycloaromatization reaction

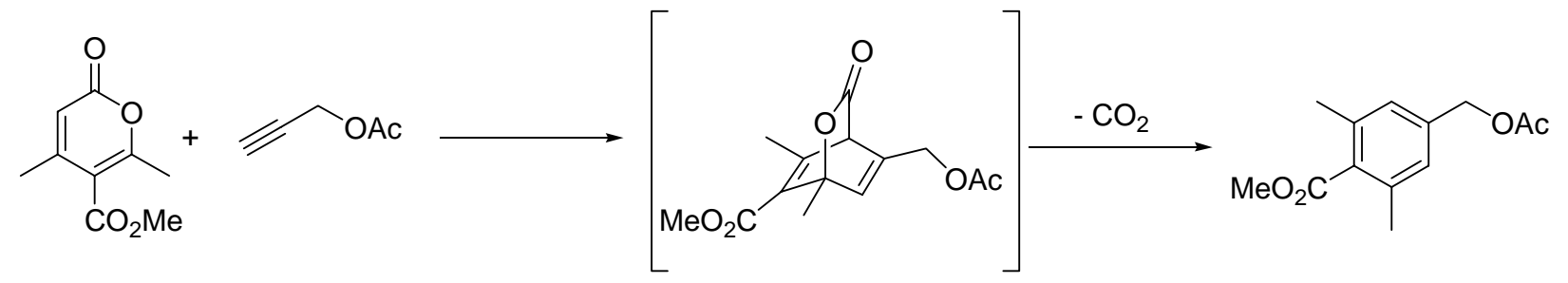

\begin{tabular}{|l|l|l|l|}
\hline & \multicolumn{2}{|l|}{ Yield $^{\mathrm{b}}$} & $10 \mathrm{~h}$ \\
\hline Conditions $^{\mathrm{a}}$ & $4 \mathrm{~h}$ & $7 \mathrm{~h}$ & $58 \%$ \\
\hline $\mathrm{A}$ & $33 \%$ & $53 \%$ & $78 \%$ \\
\hline $\mathrm{B}$ & $60 \%$ & $74 \%$ & $78 \%$ \\
\hline
\end{tabular}

${ }^{\mathrm{a} C}$ Conditions: (A) $180{ }^{\circ} \mathrm{C}$, sealed tube; (B) 0.5 equ citric acid, $180{ }^{\circ} \mathrm{C}$, sealed tube.

${ }^{\mathrm{b}} \mathrm{Y}$ ields are measured by GC/MS analysis of the reaction mixture.

A potential explanation for the efficacy of citric acid is that it appears to favor a conformation that would make 7-membered cyclic hydrogen bonding with the pyrone carbonyl feasible (Figure 3). ${ }^{14}$<smiles></smiles>

Figure 3. Possible hydrogen-bonding interaction between citric acid and the diene.

With a method to obtain reasonable yields in a moderate length of time, the reaction was extended to several substrates. A summary of the results is presented in Table 2. 
Table 2. Cycloaromatization reactions

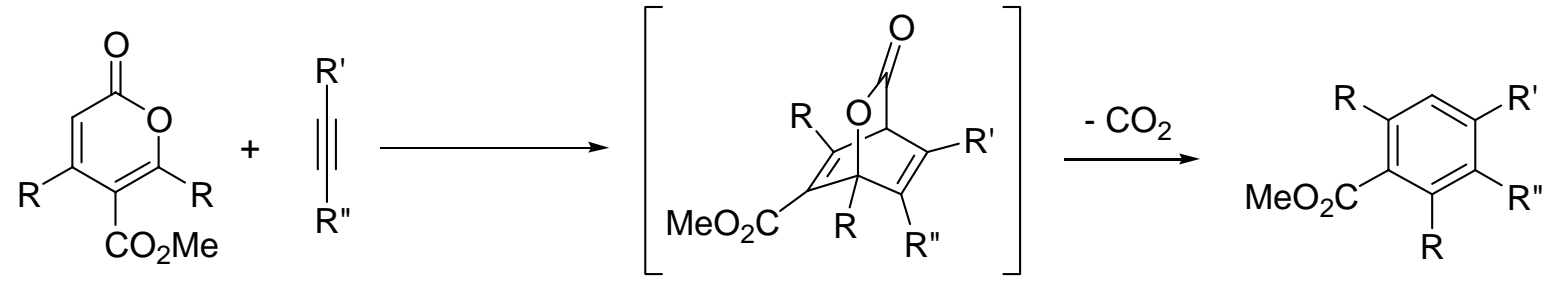

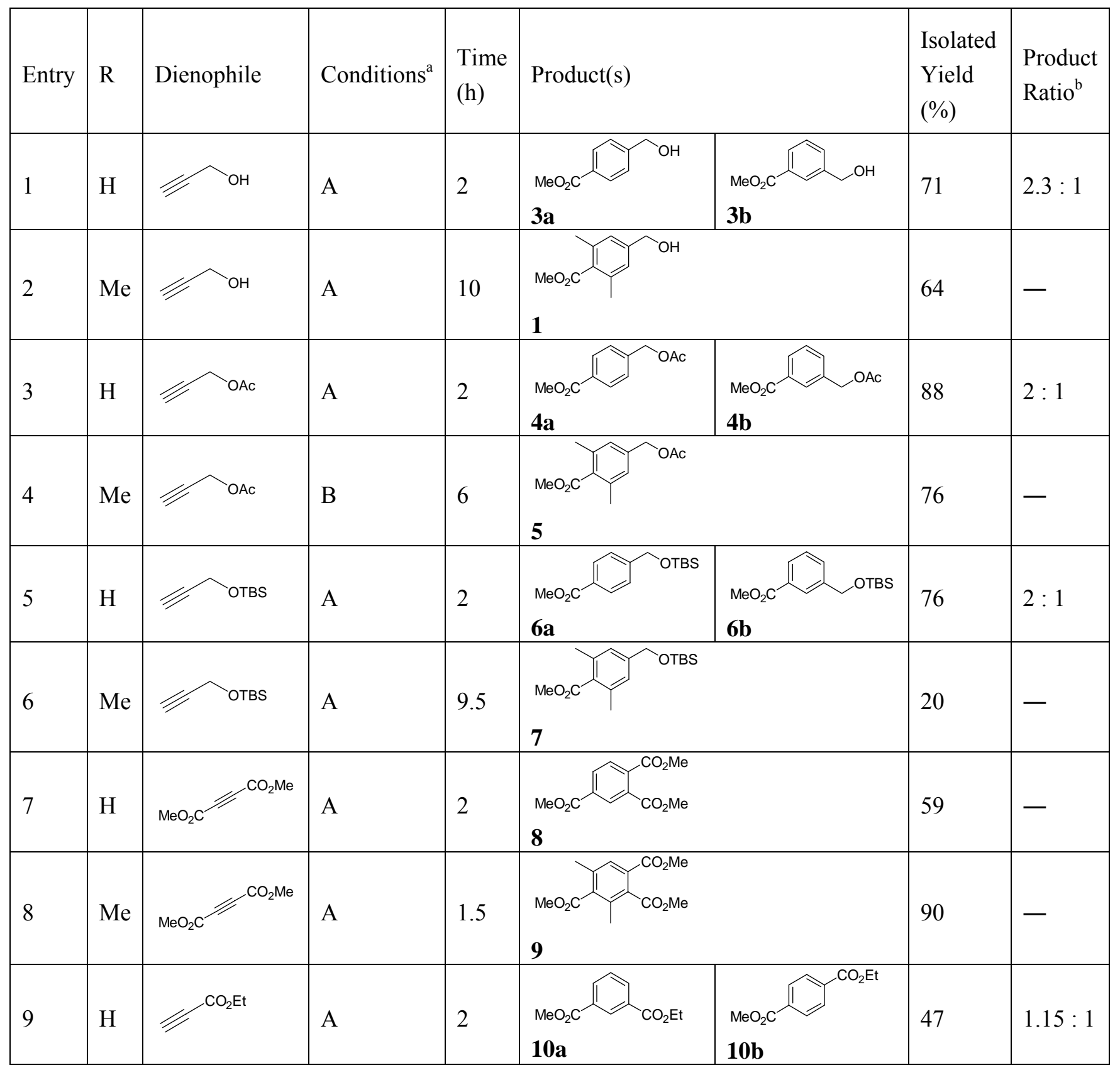


Table 1. Continued

\begin{tabular}{|c|c|c|c|c|c|c|c|c|}
\hline 10 & $\mathrm{Me}$ & 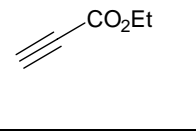 & B & 6 & 11a & $11 \mathrm{~b}$ & 56 & $1.6: 1$ \\
\hline 11 & $\mathrm{H}$ & & B & 6 & $\begin{array}{l}\mathrm{MeO}_{2} \mathrm{C}^{-} \\
\mathbf{1 2 a} \\
\end{array}$ & $\begin{array}{l}\mathrm{MeO}_{2} \mathrm{C} \\
12 \mathbf{b} \\
\end{array}$ & Quantitative & $9: 1$ \\
\hline 12 & $\mathrm{Me}$ & & B & 62.5 & $13 a$ & $\begin{array}{l}\mathrm{MeO}_{2} \mathrm{C} \\
\mathbf{1 3 b}\end{array}$ & 21 & $3: 1$ \\
\hline
\end{tabular}

${ }^{\mathrm{a}}$ Conditions: (A) $180^{\circ} \mathrm{C}$, sealed tube; (B) 0.5 equ citric acid, $180^{\circ} \mathrm{C}$, sealed tube.

${ }^{\mathrm{b}}$ Product ratios were determined by ${ }^{1} \mathrm{H}$ NMR.

The cycloadditions of methyl coumalate and methyl isodehydroacetate with propargyl alcohol (entries 1 and 2) differ greatly in rate implying that the electron-poor diene and electronrich dienophile are well matched in the first case but not in the latter. The fact that addition of methyl groups on the diene diminishes the rate suggests that these cycloadditions follow the inverse-electron-demand paradigm (steric considerations are addressed below). Enhanced regioselectivity is obtained with methyl isodehydroacetate, potentially due to a combination of steric and electronic factors.

Similar differences in regioselectivity are observed with propargyl acetate (entries 3 and 4) and TBS-protected propargyl alcohol (entries 5 and 6). Furthermore, the rate-enhancing effect of citric acid appears to be limited to the reaction producing 5 (entry 4). This may be due to the inverse-electron-demand. The hydrogen bonding illustrated in Figure 3 would render methyl isodehydroacetate slightly more electron poor, thereby facilitating the reaction. While this should also be true for the reaction of methyl isodehydroacetate with TBS-protected propargyl alcohol, the TBS group may lead to steric crowding, thereby negating the benefit of citric acid.

The use of dimethyl acetylenedicarboxylate as a dienophile leads to rapid reaction with both dienes (entries 7 and 8), which appears to indicate that the steric differences between the dienes need not have a pronounced effect on this reaction and that the traditional electron demand is at play in these cases. However, relatively sharp differences in reactivity are observed with the usage of less electron poor alkynes (entries 9 - 12). Notably, the extremely sluggish reaction between methyl isodehydroacetate and ethyl 2-butynoate (entry 12) reveals that the reactants are poorly matched. Several of these latter reactions exhibited poor regioselectivity as well.

It is noteworthy that our observations regarding the reactions that produce 10a / 10b (entry 9) and 11a / 11b (entry 10) differ from those reported previously for an extremely similar system. ${ }^{6 c}$ Using methyl coumalate with methyl propiolate in one instance and ethyl 
isodehydroacetate with methyl propiolate in another, Effenberger and Ziegler reported the opposite regioselectivity. ${ }^{6 c}$ It is possible that subtle substituent effects account for our differing observations; however, the regioselectivity reported herein appears to be in accord with the results expected based on the complementary polarity of the reactants (Scheme 2).



\section{Scheme 2}

\section{Conclusions}

Cycloaromatization of methyl isodehydroacetate and propargyl alcohol can be used to produce methyl 4-hydroxymethyl-2,6-dimethylbenzoate (1) in moderate yield and a single synthetic step. This represents a two-step reduction and a five-fold improvement in yield relative to the previously published method and should therefore facilitate the pursuit of retinal-based molecular probes.

The slow reaction of methyl isodehydroacetate with propargyl alcohol (and its derivatives), as well as the facile reaction with dimethyl acetylenedicarboxylate, suggests that this diene performs better in the traditional electron demand paradigm. This is further supported by the progressively slower reactions observed with dienophiles having less pronounced electron deficiency, such as ethyl propiolate and ethyl 2-butynoate. Steric factors appear to be of lesser importance as evidenced by the significant reduction in rate observed with ethyl propiolate (relative to dimethyl acetylenedicarboxylate) as a dienophile.

Methyl coumalate, on the other hand, acts efficiently as an ambiphilic diene as illustrated by its relatively facile reaction with all of the dienophiles examined. Steric factors alone appear not to account for the observed differences in reactivity between methyl isodehydroacetate and methyl coumalate based on the rapid reaction of both dienes with dimethyl acetylenedicarboxylate. 


\section{Experimental Section}

General Procedures. Reagents were obtained from Aldrich and were used without further purification. Sealed tube reactions were conducted in Ace pressure tubes (\#15, type A bushing). Flash column chromatography was performed using Aldrich silica gel 60 (70-230 mesh). Melting points were determined using a Mel-Temp II apparatus and are uncorrected. NMR spectra were collected on an Oxford AS400. Infrared spectra were obtained on a Mattson Instruments 4020 Galaxy Series spectrometer. GC/MS analysis was performed on a HP G1800C GCD Series II instrument. The column used was HP-5MS (Crosslinked 5\% PH ME Siloxane), $30 \mathrm{~m} \times 0.25 \mathrm{~mm} \times 0.25 \mu \mathrm{m}$ film thickness. The initial temperature was set at $150^{\circ} \mathrm{C}$, and the temperature was increased to $250{ }^{\circ} \mathrm{C}$ at a rate of $50{ }^{\circ} \mathrm{C}$ per min. Split injections of $2 \mu \mathrm{L}$ were used with a flow rate of $2.0 \mathrm{~mL} / \mathrm{min}$. The inlet and detector were both maintained at $280^{\circ} \mathrm{C}$.

Methyl 4-hydroxymethyl-2,6-dimethylbenzoate (1). Methyl isodehydroacetate (1.0 g, 5.5 $\mathrm{mmol}$ ) and propargyl alcohol $(4.0 \mathrm{~mL}, 69 \mathrm{mmol})$ were heated at $180^{\circ} \mathrm{C}$ for $10 \mathrm{~h}$ in a sealed tube. GC/MS analysis indicated 91\% 1 (2.68 $\mathrm{min}), 6 \%$ residual methyl isodehydroacetate $(2.30 \mathrm{~min})$, and 3\% unidentified impurities. The mixture was then partitioned between ethyl acetate $(50 \mathrm{~mL})$ and water $(50 \mathrm{~mL})$. The organic layer was washed with water $(2 \times 50 \mathrm{~mL})$. The combined aqueous layers were back extracted with ethyl acetate $(50 \mathrm{~mL})$, and the combined organic layers were then dried with $\mathrm{MgSO}_{4}$, filtered, and evaporated under reduced pressure. The crude product was purified by flash chromatography (gradient 10-30\% acetone/hexanes) to give $\mathbf{1}$ as pale yellow crystals $(676.4 \mathrm{mg}, 64 \%)$. mp $64.5-65.5{ }^{\circ} \mathrm{C} ; R_{f} 0.40\left(30 \%\right.$ acetone/hexanes); ${ }^{1} \mathrm{H}$ NMR (400 MHz, DMSO-d $\left.{ }_{6}\right) \delta 2.20(\mathrm{~s}, 6 \mathrm{H}), 3.81(\mathrm{~s}, 3 \mathrm{H}), 4.43(\mathrm{~d}, J=6.0 \mathrm{~Hz}, 2 \mathrm{H}), 5.21(\mathrm{t}, J=$ $5.7 \mathrm{~Hz}, 1 \mathrm{H}), 7.01(\mathrm{~s}, 2 \mathrm{H}) ;{ }^{13} \mathrm{C}$ NMR $\left(100 \mathrm{MHz}, \mathrm{DMSO}-\mathrm{d}_{6}\right) \delta 19.4,51.9,62.4,125.4,132.0$, 134.2, 143.8, 169.7; $v_{\max }(\mathrm{KBr}) / \mathrm{cm}^{-1} 3400,2952,2927,2871,1726,1611,1580,1440,1274$, 1191, 1164, 1088; LRMS (EI) 194 (45), 163 (91), 162 (91), 91 (100).

Methyl 4-(hydroxymethyl)benzoate (3a) / Methyl 3-(hydroxymethyl)benzoate (3b). A mixture of methyl coumalate $(250 \mathrm{mg}, 1.6 \mathrm{mmol})$ and propargyl alcohol $(1.2 \mathrm{~mL}, 20.3 \mathrm{mmol})$ was heated at $180{ }^{\circ} \mathrm{C}$ in a sealed tube for $2 \mathrm{~h}$. GC/MS analysis indicated $9.8 \% 3 \mathbf{b}(2.26 \mathrm{~min})$ and $90.2 \%$ 3a (2.29 $\mathrm{min})$. Column chromatography of the crude material provided a 2.3:1 mixture of 3a and $\mathbf{3 b}$ as a yellow oil (191 mg, 71\%). The data for 3a matched that of commercial samples.

Methyl 4-(acetoxymethyl)benzoate (4a) / Methyl 3-(acetoxymethyl)benzoate (4b). Methyl coumalate $(250 \mathrm{mg}, 1.6 \mathrm{mmol})$ and propargyl acetate $(2.0 \mathrm{~mL}, 20.3 \mathrm{mmol})$ were heated at $180^{\circ} \mathrm{C}$ in a sealed tube for $2 \mathrm{~h}$. GC/MS analysis indicated $11.2 \% \mathbf{4 b}(2.62 \mathrm{~min})$ and $83.5 \%$ 4a $(2.67$ min). Directly subjecting the crude reaction mixture to column chromatography $(10 \%$ acetone/hexanes) yielded a 2:1 mixture (as determined by ${ }^{1} \mathrm{H}$ NMR) of $\mathbf{4 a}$ and $\mathbf{4 b}$ as a colorless oil (300 mg, 88\%). $R_{f} 0.48$ (30\% acetone/hexanes); ${ }^{1} \mathrm{H}$ NMR (400 MHz, DMSO-d 6 ) $\delta 2.07$ (s, $3 \mathrm{H}), 3.83(\mathrm{~s}, 3 \mathrm{H}), 5.13(\mathrm{~s}, 2 \mathrm{H}), 7.47(\mathrm{~d}, J=8.8 \mathrm{~Hz}, 2 \mathrm{H}), 7.93(\mathrm{~d}, J=8.4 \mathrm{~Hz}, 2 \mathrm{H}) ;{ }^{13} \mathrm{C}$ NMR $(100$ MHz, DMSO-d $\left.\mathrm{d}_{6}\right) \delta 21.3,52.8,65.4,128.4,129.9,133.5,142.3,166.6,170.8 ; v_{\max }(\mathrm{KBr}) / \mathrm{cm}^{-1}$ 
3000, 2953, 1724, 1436, 1380, 1283, 1228, 1109, 1033, 754; LRMS (EI) 208 (11), 166 (45), 107 (100), 89 (45). ${ }^{1} \mathrm{H}$ NMR, ${ }^{13} \mathrm{C}$ NMR, and LRMS listed for 4a.

Methyl 4-acetoxymethyl-2,6-dimethylbenzoate (5). Method A. Methyl isodehydroacetate (250 $\mathrm{mg}, 1.4 \mathrm{mmol})$ and propargyl acetate $(1.8 \mathrm{~mL}, 18 \mathrm{mmol})$ were heated at $180{ }^{\circ} \mathrm{C}$ for $9.5 \mathrm{~h}$ in a sealed tube. GC/MS analysis indicated 79\% 5 (2.92 $\mathrm{min})$ and 21\% residual methyl isodehydroacetate $(2.30 \mathrm{~min})$. The crude mixture was directly subjected to column chromatography (gradient 10-20\% acetone/hexanes) to yield 5 as a colorless oil (132.9 $\mathrm{mg}$, $41 \%)$. Method $B$. Methyl isodehydroacetate $(250 \mathrm{mg}, 1.4 \mathrm{mmol})$, propargyl acetate $(1.8 \mathrm{~mL}, 18$ $\mathrm{mmol})$, and citric acid $(132 \mathrm{mg}, 0.7 \mathrm{mmol})$ were heated at $180{ }^{\circ} \mathrm{C}$ for $6 \mathrm{~h}$ in a sealed tube. The crude mixture was directly subjected to column chromatography (10\% acetone/hexanes) to yield 5 as a colorless oil (246 mg, 76\%). $R_{f} 0.54$ (30\% acetone/hexanes); ${ }^{1} \mathrm{H}$ NMR (400 MHz, DMSO$\left.\mathrm{d}_{6}\right) \delta 2.05(\mathrm{~s}, 3 \mathrm{H}), 2.21(\mathrm{~s}, 6 \mathrm{H}), 3.82(\mathrm{~s}, 3 \mathrm{H}), 4.99(\mathrm{~s}, 2 \mathrm{H}), 7.06(\mathrm{~s}, 2 \mathrm{H}) ;{ }^{13} \mathrm{C} \mathrm{NMR}(100 \mathrm{MHz}$, DMSO-d $\left._{6}\right) \delta 19.1,20.7,52.0,64.8,126.9,133.3,134.6,137.4,169.3,170.2 ; v_{\max }(\mathrm{KBr}) / \mathrm{cm}^{-1}$ 2954, 1733, 1614, 1440, 1379, 1271, 1232, 1088, 1032; LRMS (EI) 236 (15), 194 (43), 135 (100), 117 (41), 91 (46).

Methyl 4-(tert-butyldimethylsilanyloxymethyl)benzoate (6a) / Methyl 3-(tertbutyldimethylsilanyloxymethyl)benzoate (6b). A mixture of methyl coumalate (250 $\mathrm{mg}, 1.6$ $\mathrm{mmol})$ and TBS-protected propargyl alcohol $(1.2 \mathrm{~mL}, 5.7 \mathrm{mmol})$ was heated at $180{ }^{\circ} \mathrm{C}$ in a sealed tube for $2 \mathrm{~h}$. GC/MS analysis indicated $25 \% \mathbf{6 b}(3.10 \mathrm{~min})$ and $75 \% \mathbf{6 a}(3.20 \mathrm{~min})$. Column chromatography of the crude material provided a $2: 1$ mixture (as determined by ${ }^{1} \mathrm{H}$ NMR) of $\mathbf{6 a}$ and $\mathbf{6 b}$ as a pale yellow oil (345 mg, 76\%). $R_{f} 0.75$ (30\% acetone/hexanes); ${ }^{1} \mathrm{H}$ NMR (400 MHz, DMSO-d $) \delta 0.01(\mathrm{~s}, 6 \mathrm{H}), 0.83(\mathrm{~s}, 9 \mathrm{H}), 3.77(\mathrm{~s}, 3 \mathrm{H}), 4.71(\mathrm{~s}, 2 \mathrm{H}), 7.37(\mathrm{~d}, J=$ $8.4 \mathrm{~Hz}, 2 \mathrm{H}), 7.86(\mathrm{~d}, J=8.4 \mathrm{~Hz}, 2 \mathrm{H}) ;{ }^{13} \mathrm{C} \mathrm{NMR}\left(100 \mathrm{MHz}, \mathrm{DMSO}-\mathrm{d}_{6}\right) \delta 0.0,23.4,31.1,57.3$, 69.2, 131.3, 131.9, 134.5, 152.2, 171.5; $v_{\max }(\mathrm{KBr}) / \mathrm{cm}^{-1} 2953,2930,2886,2858,1727,1614$, 1436, 1285, 1200, 1103, 842, 778; LRMS (EI) 249 (4), 223 (100), 193 (38), 149 (61), 89 (49). ${ }^{1} \mathrm{H}$ NMR, ${ }^{13} \mathrm{C}$ NMR, and LRMS listed for $6 \mathbf{a}$.

Methyl 4-(tert-butyldimethylsilanyloxymethyl)-2,6-dimethylbenzoate (7). Methyl isodehydroacetate $(250 \mathrm{mg}, 1.4 \mathrm{mmol})$ and TBS-protected propargyl alcohol $(1.0 \mathrm{~mL}, 4.9 \mathrm{mmol})$ were heated at $180{ }^{\circ} \mathrm{C}$ for $9.5 \mathrm{~h}$ in a sealed tube. GC/MS analysis indicated $82 \% 7$ (3.42 $\left.\mathrm{min}\right)$, $15 \%$ residual methyl isodehydroacetate $(2.30 \mathrm{~min})$, and $3 \%$ unidentified impurities. The crude mixture was concentrated in vacuo and purified by column chromatography (gradient 10-20\% acetone/hexanes) to yield 7 as a colorless oil (84.3 mg, 20\%). $R_{f} 0.89$ (30\% acetone/hexanes); ${ }^{1} \mathrm{H}$ NMR (400 MHz, DMSO-d 6 ) $\delta 0.00$ (s, 6H), 0.83 (s, 9H), 2.15 (s, 6H), 3.76 (s, 3H), 4.58 (s, 2H), $6.94(\mathrm{~s}, 2 \mathrm{H}) ;{ }^{13} \mathrm{C}$ NMR (100 MHz, DMSO-d 6 ) $\delta-5.3,18.0,19.4,25.8,51.9,63.8,125.0$, 132.3, 134.3, 142.4, 169.5; $v_{\max }(\mathrm{KBr}) / \mathrm{cm}^{-1} 2954,2932,2890,2859,1731,1613,1461,1439$, 1265, 1088, 841; LRMS (EI) 277 (10), 251 (100), 177 (65), 89 (47).

Trimethyl 1,2,4-benzenetricarboxylate (8). A mixture of methyl coumalate (250 mg, 1.6 $\mathrm{mmol})$ and dimethyl acetylenedicarboxylate $(200 \mu \mathrm{L}, 1.6 \mathrm{mmol})$ in ethyl acetate $(1.6 \mathrm{~mL})$ was heated at $180{ }^{\circ} \mathrm{C}$ for $2 \mathrm{~h}$ in a sealed tube. GC/MS analysis indicated $100 \% 8$ (3.30 min). Column chromatography of the crude mixture (30\% acetone/hexanes) yielded the product as a pale 
yellow oil (240 mg, 59\%). $\quad R_{f} 0.43$ (30\% acetone/hexanes); ${ }^{1} \mathrm{H}$ NMR (400 MHz, DMSO-d 6 ) $\delta$ $3.83(\mathrm{~s}, 3 \mathrm{H}), 3.84(\mathrm{~s}, 3 \mathrm{H}), 3.88(\mathrm{~s}, 3 \mathrm{H}), 7.83(\mathrm{~d}, J=8.0 \mathrm{~Hz}, 1 \mathrm{H}), 8.18\left(\mathrm{dd}, J^{1}=8.0 \mathrm{~Hz}, J^{2}=1.6\right.$ $\mathrm{Hz}, 1 \mathrm{H}), 8.25(\mathrm{~d}, J=1.6 \mathrm{~Hz}, 1 \mathrm{H}) ;{ }^{13} \mathrm{C} \mathrm{NMR}\left(100 \mathrm{MHz}, \mathrm{DMSO}-\mathrm{d}_{6}\right) \delta 53.4,53.6(2 \mathrm{C}), 129.9$, 130.1, 131.7, 132.7, 133.1, 136.6, 165.4, 166.7, 167.6; $v_{\max }(\mathrm{KBr}) / \mathrm{cm}^{-1} 3004,2955,1728,1435$, 1250, 1116; LRMS (EI) 252 (8), 221 (100), 75 (12). The data match those for commercial samples.

Trimethyl 3,5-dimethyl-1,2,4-benzenetricarboxylate (9). A mixture of methyl isodehydroacetate $(250 \mathrm{mg}, 1.4 \mathrm{mmol})$ and dimethyl acetylenedicarboxylate $(590 \mu \mathrm{L}, 4.8 \mathrm{mmol})$ in ethyl acetate $(1.4 \mathrm{~mL})$ was heated at $180{ }^{\circ} \mathrm{C}$ for $1.5 \mathrm{~h}$ in a sealed tube. GC/MS analysis indicated 93\% 9 (3.64 min), 6\% unidentified impurity (3.35 min), and 1\% residual methyl isodehydroacetate $(2.30 \mathrm{~min})$. The crude mixture was directly subjected to column chromatography (10\% acetone/hexanes), which yielded the product as a pale yellow oil (305 $\mathrm{mg}$, 90\%). $\quad R_{f} 0.59$ (30\% acetone/hexanes); ${ }^{1} \mathrm{H}$ NMR (400 MHz, DMSO-d 6 ) $\delta 2.14(\mathrm{~s}, 3 \mathrm{H}), 2.27(\mathrm{~s}$, $3 \mathrm{H}), 3.81(\mathrm{~s}, 3 \mathrm{H}), 3.81(\mathrm{~s}, 3 \mathrm{H}), 3.88(\mathrm{~s}, 3 \mathrm{H}), 7.70(\mathrm{~s}, 1 \mathrm{H}) ;{ }^{13} \mathrm{C}$ NMR (100 MHz, DMSO-d 6$) \delta$ $16.9,19.5,53.2,53.3,53.4,128.9,129.5,132.4,133.6,136.7,139.2,165.9,168.8,168.9$; $v_{\max }$ $(\mathrm{KBr}) / \mathrm{cm}^{-1}$ 3000, 2953, 1732, 1438, 1255, 1168, 1113, 1035; LRMS (EI) 280 (3), 249 (52), 162 (100). The product resulting from the use of ethyl isodehydroacetate is a known compound prepared in a similar fashion. ${ }^{6 \mathrm{~d}}$

Ethyl methyl isophthalate (10a) / Ethyl methyl terephthalate (10b). A mixture of methyl coumalate $(250 \mathrm{mg}, 1.6 \mathrm{mmol})$ and ethyl propiolate $(580 \mu \mathrm{L}, 5.7 \mathrm{mmol})$ in ethyl acetate $(1.6 \mathrm{~mL})$ was heated at $180{ }^{\circ} \mathrm{C}$ in a sealed tube for $2 \mathrm{~h}$. GC/MS analysis indicated $100 \%$ poorly resolved regioisomers (2.52 and $2.53 \mathrm{~min}$ ). Column chromatography of the crude material gave a 1.15:1 mixture (as shown by ${ }^{1} \mathrm{H}$ NMR) of 10a and 10b as a colorless oil (158 mg, 47\%). $R_{f} 0.60$ (30\% acetone/hexanes); ${ }^{1} \mathrm{H}$ NMR (400 MHz, DMSO- $\left.\mathrm{d}_{6}\right) \delta 1.31$ (m, 6H regioisomers overlap), 3.86 (two s, $3 \mathrm{H}$ each, regioisomers overlap), 4.31 (m, 4H, regioisomers overlap), 7.65 (apparent $\mathrm{t}, J=$ $8.2 \mathrm{~Hz}, 1 \mathrm{H}), 8.02$ (s, 4H, minor), $8.16\left(\mathrm{dd}, J^{1}=8.0 \mathrm{~Hz}, J^{2}=1.6 \mathrm{~Hz}, 2 \mathrm{H}\right), 8.42$ (apparent t, $J=1.2$ $\mathrm{Hz}, 1 \mathrm{H}) ;{ }^{13} \mathrm{C}$ NMR (100 MHz, DMSO-d 6 ) $\delta 14.7,14.7,53.1,53.1,61.8,61.9,130.0,130.1$, $130.1,130.8,131.1,134.1,134.2,134.2,134.4,165.5,165.6,166.1,166.2 ; v_{\max }(\mathrm{KBr}) / \mathrm{cm}^{-1}$ 2983, 2954, 1727, 1437, 1274, 1245, 1103, 730; LRMS (EI) 208 (13), 163 (100), 149 (50), 76 (51), 50 (44).

Ethyl methyl 2,4-dimethylisophthalate (11a) / Ethyl methyl 3,5-dimethylterephthalate (11b). A mixture of methyl isodehydroacetate $(250 \mathrm{mg}, 1.4 \mathrm{mmol})$, ethyl propiolate $(490 \mu \mathrm{L}, 4.8$ $\mathrm{mmol})$, and citric acid $(132 \mathrm{mg}, 0.7 \mathrm{mmol})$ in ethyl acetate $(1.4 \mathrm{~mL})$ was heated at $180{ }^{\circ} \mathrm{C}$ for $6 \mathrm{~h}$ in a sealed tube. GC/MS analysis indicated 100\% poorly resolved regioisomers (2.91 and 2.94 $\mathrm{min})$. Directly subjecting the mixture to column chromatography ( $10 \%$ acetone/hexanes) yielded a 1.6:1 ratio of $\mathbf{1 1 a}$ and $\mathbf{1 1 b}$ as a colorless oil $(183 \mathrm{mg}, 56 \%)$. The ratio was determined by ${ }^{1} \mathrm{H}$ NMR. $R_{f} 0.57$ (30\% acetone/hexanes); ${ }^{1} \mathrm{H}$ NMR (400 MHz, DMSO-d $\left.{ }_{6}\right) \delta 1.28(\mathrm{~m}, 6 \mathrm{H}$, regioisomers overlap), $2.22(\mathrm{~s}, 3 \mathrm{H}), 2.25(\mathrm{~s}, 6 \mathrm{H}$, minor), $2.35(\mathrm{~s}, 3 \mathrm{H}), 3.85(\mathrm{~s}, 3 \mathrm{H}), 3.86(\mathrm{~s}, 3 \mathrm{H}$, minor), 4.26 (m, 4H, regioisomers overlap), 7.19 (d, $J=8.0 \mathrm{~Hz}, 1 \mathrm{H}), 7.65$ (s, 2H, minor), 7.72 $(\mathrm{d}, J=8.0 \mathrm{~Hz}, 1 \mathrm{H}) ;{ }^{13} \mathrm{C}$ NMR $\left(100 \mathrm{MHz}, \mathrm{DMSO}-\mathrm{d}_{6}\right) \delta 14.7,14.8,18.1,19.6,19.8,52.9,52.9$, 
$61.4,61.6,128.2,128.7,129.0,131.2,131.3,135.4,135.6,136.8,138.6,138.8,165.9,167.2$, 169.5, 169.9; $v_{\max }(\mathrm{KBr}) / \mathrm{cm}^{-1} 2982,2953,1727,1598,1437,1266,1231,1125,1037,771$; LRMS (EI) 236 (50), 207 (100), 191 (88), 75 (69).

Ethyl methyl 6-methylisophthalate (12a) / Ethyl methyl 2-methylterephthalate (12b). A mixture of methyl coumalate $(250 \mathrm{mg}, 1.6 \mathrm{mmol})$, ethyl 2-butynoate (400 $\mu \mathrm{L}, 3.4 \mathrm{mmol})$, and citric acid $(156 \mathrm{mg}, 0.8 \mathrm{mmol})$ in ethyl acetate $(1.6 \mathrm{~mL})$ was heated at $180{ }^{\circ} \mathrm{C}$ in a sealed tube for $6 \mathrm{~h}$. GC/MS analysis indicated 3\% residual methyl coumalate (1.64 min) and $97 \%$ 12a and 12b (2.79 min). Column chromatography of the crude mixture resulted in a 9:1 ratio (as determined by ${ }^{1} \mathrm{H}$ NMR) of 12a and $\mathbf{1 2 b}$ as white needles (quantitative). $R_{f} 0.58$ (30\% acetone/hexanes); mp $68.5-69.5{ }^{\circ} \mathrm{C} ;{ }^{1} \mathrm{H}$ NMR (400 MHz, DMSO-d 6 ) $\delta 1.30(\mathrm{t}, J=7.2 \mathrm{~Hz}, 3 \mathrm{H}), 2.55(\mathrm{~s}, 3 \mathrm{H}), 3.84(\mathrm{~s}$, $3 \mathrm{H}), 4.29$ (q, $J=7.2 \mathrm{~Hz}, 2 \mathrm{H}), 7.44(\mathrm{~d}, J=8.0 \mathrm{~Hz}, 1 \mathrm{H}), 7.97\left(\mathrm{dd}, J^{1}=1.6 \mathrm{~Hz}, J^{2}=8.0 \mathrm{~Hz}, 1 \mathrm{H}\right)$, $8.32(\mathrm{~d}, J=2.0 \mathrm{~Hz}, 1 \mathrm{H}) ;{ }^{13} \mathrm{C}$ NMR $\left(100 \mathrm{MHz}, \mathrm{DMSO}-\mathrm{d}_{6}\right) \delta 14.7,21.9,52.9,61.6,127.2,128.2$, 131.3, 132.8, 133.0, 145.4, 166.1, 166.7; $v_{\max }(\mathrm{KBr}) / \mathrm{cm}^{-1} 2979,2953,1716,1436,1292,1244$, 1076, 751; LRMS (EI) 222 (39), 177 (85), 163 (100), 89 (58). ${ }^{1} \mathrm{H}$ NMR, ${ }^{13} \mathrm{C}$ NMR, and LRMS listed for 12a. The identity of the major regioisomer (12a) was determined by the NOESY correlation between the protons at 2.55 and $7.44 \mathrm{ppm}$.

Ethyl methyl 2,4,6-trimethylisophthalate (13a) / Ethyl methyl 2,3,5-trimethylterephthalate (13b). A mixture of methyl isodehydroacetate $(250 \mathrm{mg}, 1.4 \mathrm{mmol})$, ethyl 2-butynoate $(560 \mu \mathrm{L}$, $4.8 \mathrm{mmol})$, and citric acid (132 mg, $0.7 \mathrm{mmol})$ in ethyl acetate $(1.4 \mathrm{~mL})$ was heated at $180{ }^{\circ} \mathrm{C}$ for $62.5 \mathrm{~h}$ in a sealed tube. GC/MS analysis indicated $14 \%$ residual methyl isodehydroacetate $(2.30$ $\mathrm{min}$ ), $60 \%$ 13a $(3.12 \mathrm{~min}$ ), and $22 \% 13 \mathbf{b}$ (3.27 $\mathrm{min})$. The crude material was subjected to column chromatography (10\% acetone/hexanes) to yield the product as a colorless oil (71 mg, $21 \%)$, which was a $3: 1$ mixture of $\mathbf{1 3 a}$ and $\mathbf{1 3 b}$ as shown by ${ }^{1} \mathrm{H}$ NMR. $R_{f} 0.59(30 \%$ acetone/hexanes); ${ }^{1} \mathrm{H}$ NMR (400 MHz, DMSO- $\left.\mathrm{d}_{6}\right) \delta 1.27$ (m, 6H, regioisomers overlap), 2.10 (s, $3 \mathrm{H}), 2.13$ (s, 3H, minor), 2.18 (s, 3H, minor), $2.18(\mathrm{~s}, 3 \mathrm{H}), 2.19$ (s, 3H), 2.30 (s, 3H, minor), 3.83 $(\mathrm{s}, 3 \mathrm{H}), 3.85(\mathrm{~s}, 3 \mathrm{H}$, minor), $4.30(\mathrm{~m}, 4 \mathrm{H}$, regioisomers overlap), $7.02(\mathrm{~s}, 1 \mathrm{H}), 7.37(\mathrm{~s}, 1 \mathrm{H}$, minor); ${ }^{13} \mathrm{C}$ NMR (100 MHz, DMSO-d 6 ) $\delta$ 14.7, 14.7, 16.7, 17.4, 17.7, 19.2, 19.6, 19.7, 52.8, $52.9,61.5,61.6,128.5,129.9,131.4,131.6,132.9,133.0,133.1,134.5,134.7,136.0,136.0$, 137.8, 168.3, 169.2, 169.8, 170.2; $v_{\max }(\mathrm{KBr}) / \mathrm{cm}^{-1} 2981,2953,1732,1438,1254,1204,1109$, 1037; LRMS (EI) 250 (46), 219 (43), 205 (100), 176 (29). The identity of the major regioisomer (13a) was determined by the NOESY correlation between the proton appearing $7.02 \mathrm{ppm}$ and methyl groups at 2.18 and 2.19 ppm. Further evidence was provided by the absence of a NOESY correlation between benzylic protons.

\section{Acknowledgements}

The authors thank the W\&J College Faculty and Staff Entrepreneurial Fund and the HHMI Undergraduate Science Program Education Grant (71100-552202) at W\&J College for their generous support of this work. T.J.S. was a participant in the ACS Project SEED program, which 
was supported by donations from Bayer MaterialScience LLC, Eastman Chemical Company, Ferro Corporation, LabChem, Inc., Lexicon Pharmaceuticals, PPG Industries, the Project SEED Endowment, and Westinghouse. NMR spectra were acquired on an instrument provided by the National Science Foundation's Major Research Instrumentation Program (Award No. CHE0216075).

\section{References and Notes}

1. (a) Afarinkia, K.; Posner, G. H. Tetrahedron Lett. 1992, 33, 7839. (b) Cho, C.-G.; Park, J.S.; Jung, I.-H.; Lee, H. Tetrahedron Lett. 2001, 42, 1065. (c) Cho, C.-G.; Kim, Y.-W.; Lim, Y.-K.; Park, J.-S.; Lee, H.; Koo, S. J. Org. Chem. 2002, 67, 290. (d) Lee, J.-H.; Kim, W.-S.; Lee, Y.-Y.; Cho, C.-G. Tetrahedron Lett. 2002, 43, 5779. (e) Afarinkia, K.; Bearpark, M. J.; Ndibwami, A. J. Org. Chem. 2005, 70, 1122.

2. Some literature suggests that this cycloaddition is not a concerted Diels-Alder reaction: Jung, M. E.; Street, L. J.; Usui, Y. J. Am. Chem. Soc. 1986, 108, 6810.

3. Jung, M. E.; Hagenah, J. A. J. Org. Chem. 1987, 52, 1889.

4. Balázs, L; Kádas, I.; Tõke, L. Tetrahedron Lett. 2000, 41, 7583.

5. Sonnewald, U.; Seltzer, S. J. Labelled Compd. Radiopharm. 1986, 24, 787.

6. (a) Salomon, R. G.; Burns, J. R.; Dominic, W. J. J. Org. Chem. 1976, 41, 2918. (b) Gingrich, H. L.; Roush, D. M.; Van Saun, W. A. J. Org. Chem. 1983, 48, 4869. (c) Effenberger, F.; Ziegler, T. Chem. Ber. 1987, 120, 1339. (d) Ziegler, T.; Layh, M.; Effenberger, F. Chem. Ber. 1987, 120, 1347. (e) Dieter, R. K.; Balke, W. H.; Fishpaugh, J. R. Tetrahedron 1988, 44, 1915. (f) Afarinkia, K.; Vinader, V.; Nelson, T. D.; Posner, G. H. Tetrahedron 1992, 48, 9111.

7. Kranjc, K.; Štefane, B.; Polanc, S.; Kočevar, M. J. Org. Chem. 2004, 69, 3190.

8. Imagawa, T.; Nakagawa, T.; Kawanasi, M.; Sisido, K. Bull. Chem. Soc. Jpn. 1979, 52, 1506.

9. Harmata, M.; Sharma, U. Org. Lett. 2000, 2, 2703.

10. Powell, D. A.; Batey, R. A. Org. Lett. 2002, 4, 2913.

11. Zhu, Z.; Espenson, J. H. J. Am. Chem. Soc. 1997, 119, 3507.

12. Ryu, D. H.; Zhou, G.; Corey, E. J. Org. Lett. 2005, 7, 1633.

13. Ghosh, A. K.; Matsuda, H. Org. Lett. 1999, 1, 2157.

14. Glusker, J. P. Acc. Chem. Res. 1980, 13, 345. 